Western University

Scholarship@Western

Department of Economics Research Reports

Economics Working Papers Archive

1990

\title{
Dynamic Increasing Returns, Technology and Economic Growth in a Small Open Economy
}

Ka-yiu Michael Fung

Jota Ishikawa

Follow this and additional works at: https://ir.lib.uwo.ca/economicsresrpt

Part of the Economics Commons

Citation of this paper:

Fung, Ka-yiu Michael, Jota Ishikawa. "Dynamic Increasing Returns, Technology and Economic Growth in a Small Open Economy." Department of Economics Research Reports, 9013. London, ON: Department of Economics, University of Western Ontario (1990). 
RESEARCH REPORT 9013

DYNAMIC INCREASING RETURNS, TECHNOLOGY AND ECONOMIC GROWTH

IN A SMALL OPEN ECONOMY

by

\author{
Ka-yiu Michael Fung \\ and \\ Jota Ishikawa
}

September 1990

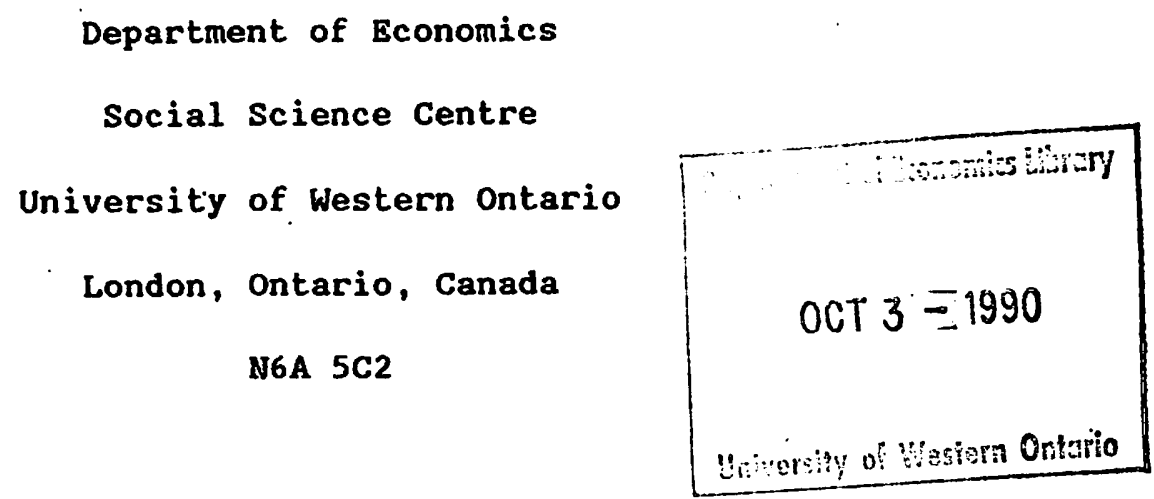




\title{
Dynamic Increasing Returns, Technology and Economic Growth in a Small Open Economy
}

\author{
Ka-yiu Michael Fung \\ and \\ Jota Ishikawa* \\ Department of Economics \\ University of Western Ontario \\ London, Ontario N6A 5C2 \\ Canada \\ First Draft, January 1989 \\ Revised, September 1990
}

\begin{abstract}
A two-final-good and knowledge-based growth model is constructed to study growth patterns in a small open economy. The source of growth is the introduction of new intermediate goods as a result of $R \& D$, which in turn generates dynamic increasing returns in both the production of one final good and $R \& D$. The results obtained in the model are consistent with intercountry differences in growth patterns. Depending on the technology level, a zerogrowth equilibrium appears. However, there exist some temporary policies that can help the economy take off. If the economy grows, the growth rate increases. Moreover, the share of the labor force employed by the constant-returns final-good sector decreases in the process of growth.
\end{abstract}

"An earlier version of this paper circulated under the title "Differentiated Intermediate Goods, Changes in Production Mix, and Growth in a Small Open Economy". We would like to thank Ake Blomqvist, David Burgess, Jim Feehan, Gene Grossman, Ig Horstmann, Peter Howitt, Jim Markusen, Jim Melvin, Alasdair Smith, and Ian Wooton for their comments and discussions on earlier drafts. We are also indebted to two referees for their helpful comments. All remaining errors are, of course, our own responsibility. 


\section{Dynamic Increasing Returns, Technology, and Economic Growth in a Small Open Economy}

\section{Introduction}

A two-sector neoclassical framework has been adopted to study relationships between trade and economic growth in a number of works. ${ }^{1}$ In the neoclassical framework, however, economic growth sometimes crucially depends on some exogenous parameters, such as exogenous technological progress and an exogenous saving rate. Moreover, it has been pointed out that the neoclassical framework cannot satisfactorily explain many empirical phenomena, such as the diversity in per capita GDP growth rates across countries and the lack of negative correlation between income levels and growth rates. ${ }^{2}$

Recently, knowledge-based growth models have been developed to overcome the above criticism in the area of macroeconomics in response to the thrust generated by Romer (1986) and Lucas (1988). In those frameworks, cumulative knowledge plays an important role in generating endogenously determined and sustained growth. Those models primarily evaluate a closed economy with only one final good. The purpose of this paper is to provide a growth model of a multiple-sector, small open economy (SOE) in the context of knowledgebased growth. In particular, we are concerned with the observation that the patterns of economic growth are quite different across countries [see Lucas (1988)]. We wonder why some economies, such as South Korea and Taiwan, have been growing successfully, while numerous others have not. This paper tries to construct a model consistent with this observation.

The specific features of our model are as follows. There are two primary factors, labor and land. In addition to two final-good sectors $(X$ and $Y$ ), we introduce two more sectors into the model: the R\&D sector and the intermediate-good sector. ${ }^{3}$ Good $Y$ is produced under constant returns to scale (CRS) with labor and a specific factor, land. Good $X$ is

\footnotetext{
${ }^{1}$ Findlay (1984) and Smith (1984) survey this literature.

${ }^{2}$.Romer (1986) discusses these empirical results.

${ }^{3}$ The two-sectur neoclassical growth models commonly assume that one sector produces a consumption good and the other produces an investment good. In our model, however, both final-good sectors produce consumption goods.
} 
produced with differentiated intermediate goods alone with a CRS, CES production function, and the intermediate goods are in turn produced with labor alone, provided the technology is available. Monopolistic competition prevails in the intermediate-good market. The number of producible intermediate goods can be augmented as a result of $R \& D$.

The above relationship between good $X$ and the differentiated intermediate goods generates IRS in the production of good $X$. Using a CES production function, Ethier (1982) originally introduces the Dixit and Stiglitz (1977) type of differentiated intermediate goods into a static general equilibrium framework to provide a micro-foundation of Marshallian external economies. ${ }^{4}$ In the present study, a R\&D sector is introduced into his framework to construct a dynamic framework with IRS. Insight from Romer (1988) is borrowed to specify the characteristics of this $R \& D$ sector. The productivity of labor in $R \& D$ crucially depends on the cumulative knowledge in the $R \& D$ sector. The source of economic growth in this paper is the introduction of new intermediate goods as a result of $R \& D$, which in turn generates dynamic IRS in both the production of good $X$ and $\mathrm{R} \& \mathrm{D}$.

We focus on a SOE because most developing economies, including South Korea and Taiwan, can be regarded as SOE's. Moreover, the assumption of a SOE simplifies our analysis. Specifically, it is assumed that the SOE trades two final goods at exogenously given world prices and have access to the world capital market at an exogenously given world interest rate. Thus, we can abstract from the complex intra-temporal and inter-temporal terms-oftrade conditions and the preference structure. As in Grossman and Helpman (1989b), it is also assumed that intermediate goods are not traded. ${ }^{5}$

Three interesting results are obtained in the model. First, we have two kinds of equilibria: a low-level equilibrium and a high-level equilibrium. In the low-level equilibrium, the economy does not grow at all (i.e., the low-level equilibrium is in fact a zero-growth equilibrium),

\footnotetext{
${ }^{4}$ Ethier (1982) analyzes the positive issues in trade theory. Markusen $(1988,1989)$ uses the same framework to study the welfare implications of trade in services and migration. Okuno-Fujiwara (1988) provides an alternative micro-foundation by using a Cournot concept in the presence of imperfect competition.

${ }^{5}$ As one referee has pointed out, the economy is not completely open because of this assumption. This assumption will be the driving force behind our interesting and realistic results, i.e., intercountry differences in growth patterns. Grossman and Helpman (1989a) use a similar 2-country model with free trade in intermediate goods to show that both countries will grow at the same rate in the long-run.
} 
while in the high-level equilibrium, the economy continues to grow (i.e., the high-level equilibrium is a positive-growth equilibrium). Depending on the initial stock of knowledge in the R\&D sector, or the initial technology level, either a zero-growth equilibrium or a high-level equilibrium appears. It should be noted that we do not have multiple equilibria. ${ }^{6}$ The initial technology level uniquely determines the equilibrium in our model. Also different technology levels lead to different income levels. Thus, the technology level is crucial in determining both levels and growth rates of per capita income. It is also shown that the growth rate increases in the process of economic growth. This result is consistent with Romer's (1986) work. Romer (1986) discusses empirical support of the increasing growth rate hypothesis and shows its possibility in a 1-final-good economy with IRS. The above results in this paper are consistent with the observed diversity across countries in both levels and rates of growth of per capita income.

Second, there exist temporary policies that move the economy from a low-level equilibrium to a high-level equilibrium to initiate economic growth. It would be interesting to compare policies such as taxes and subsidies, and derive the optimal level of subsidy or tax. However, there are at least two difficulties associated with this exercise. Since the present study does not deal with a steady state, it is difficult to evaluate these policies. Moreover, there are two distortions in our model: externalities in R\&D and monopolistic competition in the intermediate-good market, which make the ranking of policies difficult. Because of these two distortions, a growth enhancing policy may not necessarily be a welfare improving policy [see also Grossman and Helpman (1989b)]. In particular, permanent rather than temporary policies will be needed to achieve the first-best equilibrium. Thus, we focus on positive aspects of temporary policies in our study. ${ }^{7}$

Third, the labor force is reallocated from the $Y$ sector to the R\&D and the intermediate-

\footnotetext{
${ }^{6}$ Markusen (1988), Matsuyama (1989), and Murphy et al. (1989) also analyze the possibility of a lowlevel and a high-level equilibrium in different frameworks. In contrast with our model, they have multiple equilibria.

${ }^{7}$ Matsuyama (1989) also discusses the role of government policy in moving the economy from a low-level equilibrium to a high-level equilibrium in a dynamic framework, though there is no endogenous growth in his model. He also discusses only second-best policies that may bring out a high-level equilibrium.
} 
good sector in the process of economic growth. Thus, the share of good $X$ in the value of the total final output can increase in the process of economic growth. This change obtained in our model can be consistent with the observation by Kuznets (1957) and Chenery (1960) that the share of manufactured product in the composition of output increases as per capita income increases.

Our framework is similar to those in Grossman and Helpman (1989a,b). In particular, using a SOE framework, Grossman and Helpman (1989b) study various policies affecting for growth and welfare. ${ }^{8}$ They also assume two primary factors, two final goods, differentiated intermediate goods, and R\&D in their model. However, differentiated intermediate goods are inputs for the production of both final goods in their model, and hence the productivity increases in both final-good sectors. They focus on a steady state and both final-goods sectors grow at the same rate in the steady state. Thus, their steady state analysis cannot generate the above three results that we obtained. Instead, the steady state analysis allows the derivation of the welfare implications of R\&D subsidies and trade policies. Even in their analysis, however, they cannot rank those policies because of the two distortions mentioned above.

The remainder of this paper is organized as follows. Section 2 describes the basic model. In Section 3, economic growth in a multiple-sector, SOE is analyzed. It is shown that the technology level is a key to determining a dynamic path. The condition for zero-growth is derived and then, in Section 4, corresponding policies are discussed. An exogenous increase in labor is also analyzed. Section 5 discusses conclusions from the analysis.

\footnotetext{
${ }^{8}$ There are two other related works that also adopt knowledge-based growth frameworks with an emphasis on human capital accumulation to examine interactions between international trade and economic growth. Lucas (1988) uses a 2-final-good model in which the productivity of each final good depends on the level of the stock of sector-specific human capital. This sector-specific human capital is accumulated by learning by doing at a sector-specific rate. In a global trade equilibrium, each country specializes in the production of one final good. In his model, both the growth rate and the effect of trade policy crucially depend on the type of specialization that is determined by the endowments of sector-specific human capital. Manning (1982) studies the optimal educational and trade policies for a SOE by introducing an education sector and assuming the heterogeneity of the labor force (skilled and unskilled laborers). By solving the planner's problem, he shows that specialization is the most likely pattern of production. In the present model, it is shown that complete specialization is a special case in which the initial technology level is not sufficiently high.
} 


\section{The Basic Model}

We examine a SOE with two primary factors (labor $(L)$ and land $(T)$ ), differentiated intermediate goods $(S(i))$, know-how or technology $(N)$ to produce intermediate goods, knowledge in the $\mathrm{R} \& \mathrm{D}$ sector $(K)$, and two final goods $(X$ and $Y)$. The endowments of primary factors are fixed and normalized to be equal to one over time. Production, trade, and consumption occur instantaneously. The SOE trades final goods at exogenously given prices and has access to the world capital market at an exogenously given instantaneous interest rate. Letting good $X$ be the numeraire, the world price of good $Y$ is $P^{\star}$ and the world instantaneous interest rate is $r$. For simplicity, both $P^{\star}$ and $r$ are assumed to be positive and fixed over time.

In the spirit of Jensen and Thursby (1986), Romer (1988), and Grossman and Helpman $(1989 \mathrm{a}, \mathrm{b})$, we assume that new technology or know-how to produce new intermediate goods can be invented in the R\&D activity, using labor alone, and that the productivity of labor in $R \& D$ depends on the cumulative knowledge in $R \& D$. Knowledge is created as a byproduct in the process of R\&D. It is assumed that knowledge is purely external to any firms in the R\&D sector. That is, once knowledge is created, it immediately becomes a public good which is freely available. Specifically, a flow of know-how (technology), $\dot{N}$, is formed by: ${ }^{\ominus}$

$$
\dot{N}=\delta K L_{n},
$$

where a dot over a variable denotes the derivative with respect to time, $t, \delta$ is a positive productivity parameter, and $L_{n}$ is labor allocated to the R\&D sector. We assume the stock of knowledge, $K$, increases in proportion to the stock of know-how, $N$, and units for $K$ are chosen so that $K=N$. That is, $N$ measures the stock of knowledge in R\&D as well as the stock of know-how. Thus, we have

$$
\dot{N}=\delta N L_{n}
$$

\footnotetext{
${ }^{9}$ Romer (1988) and Grossman and Helpman (1989a,b) adopt the same function in R\&D. Jensen and Thursby (1986) and Schmitz (1987) also assume similar functions in R\&D. All variables depend on time, but we suppress the $t$-variables when no confusion is caused by doing so.
} 
It should be noted that the cumulative knowledge is given at any point in time and thus the production function (1) exhibits CRS at any point in time. In the R\&D sector, the wage rate, $W_{n}$, and the price of know-how, $P_{n}$, are related in the following way:

$$
W_{n}=\delta N P_{n}
$$

It is assumed that each intermediate good is produced by a single firm and that the production of any intermediate good requires know-how and labor. At any point in time $t$, the type of technology used by the intermediate-good sector is indexed by $i \in[0, N(t)]$. Each $i$ corresponds to a particular type of technology to produce a particular type of intermediate good. Thus, $N$ also measures the variety of intermediate goods available. The number of producible intermediate goods can be augmented as a result of $R \& D$.

The assumption is that the producer of $S(i)$ must pay a fixed cost, $P_{n}$, to obtain knowhow from the $R \& D$ sector. Once the fixed cost is incurred, he/she can produce any amount of $S(i)$ at each point in time. ${ }^{10}$ We further assume that one unit of labor can produce one unit of $S(i)$.

Good $Y$ is produced under CRS with labor and a specific factor, land;

$$
Y=F\left(L_{y}, T\right)=F\left(L_{y}, 1\right) \equiv f\left(L_{y}\right) ; \quad f^{\prime}>0, \quad f^{\prime \prime}<0, \quad \lim _{L_{y} \rightarrow 0} f^{\prime}=\infty,
$$

where $L_{y}$ is the labor employment in the $Y$ sector. Thus, the wage rate in the $Y$ sector, $\mathrm{W}_{y}$, and the rental rate on land, $R$, are, respectively, given by

$$
\begin{aligned}
& W_{y}=P f^{\prime}\left(L_{y}\right), \\
& R=P\left[f\left(L_{y}\right)-L_{y} f^{\prime}\left(L_{y}\right)\right],
\end{aligned}
$$

where $P$ is the price of good $Y$.

For simplicity, good $X$ is assumed to be produced with intermediate goods alone. ${ }^{11}$ To make the model tractable, the $S(i)$ 's are assumed to be symmetric but imperfect substitutes

\footnotetext{
${ }^{10}$ As Grossman and Helpman (1989a) note, we can consider that R\&D produces "blueprints" which are perfectly appropriable by the originator.

${ }^{11}$ Ethier (1982) and Markusen (1989) also make the same assumption.
} 
in the production of good $X$. Specifically, the production function is given by the following CRS, CES function:

$$
X=\left(\int_{0}^{N} S(i)^{\beta} d i\right)^{1 / \beta}, \quad 0<\beta<1 .
$$

As is discussed in Grossman and Helpman (1989a), this production function has important characteristics. First, with a given variety of available intermediate goods, the production function exhibits CRS and hence there exists no problem with the aggregation of the individual firm outputs. Second, augmentation of the variety of available intermediate goods increases the total factor productivity. Thus, good $X$ is produced under dynamic IRS in the presence of R\&D activity. However, these economies of scale are at the sector level and are external to the individual producers in good $X$.

In this model, as in Romer (1988), Grossman and Helpman (1989a,b), and Markusen (1989), it is assumed that all agents, other than the intermediate-good suppliers, take their input and output prices as given and that monopolistic competition prevails in the intermediate-good market. The monopolistic-competition equilibrium can be solved as follows. The demand for a particular intermediate good, $S(i)$, is obtained from the following maximization problem of the producer of good $X$;

$$
\max _{S(i)}\left[\left(\int_{0}^{N} S(j)^{\beta} d j\right)^{1 / \beta}-\int_{0}^{N} P_{s}(j) S(j) d j\right]
$$

where $P_{s}(i)$ is the price of intermediate good $S(i)$. Noting that the producer of $S(i)$ takes $P_{\diamond}(j)(i \neq j)$ as given in monopolistic competition, we obtain the following inverse demand function from the first-order condition:

$$
P_{s}(i)=\left[\int_{0}^{N} S(j)^{\beta} d j\right]^{\frac{1}{\beta}-1} S(i)^{\beta-1}=X^{1-\beta} S(i)^{\beta-1} .
$$

A continuum of intermediate goods implies that the variety of intermediate goods is so large that each intermediate-good producer views the output of good $X$ as given. Taking $W_{s}$ and $X$ as given, the producer of $S(i)$ who has already paid the fixed cost faces the following maximization problem; 


$$
\pi(i) \equiv \max _{S(i)}\left[P_{s}(i) S(i)-W_{s} S(i)\right],
$$

where $W_{s}$ is the wage rate in the intermediate good sector. Since the producer is a monopolistic supplier of $S(i)$, he/she maximizes profit subject to equation (7) and then the first-order condition implies:

$$
W_{s}=\beta\left[\int_{0}^{N} S(j)^{\beta} d j\right]^{\frac{1}{\beta}-1} S(i)^{\beta-1} .
$$

In the equilibrium, the intertemporal zero-profit condition holds with free entry by entrepreneurs in $R \& D$ activity. That is, free entry into $R \& D$ ensures that the sum of the discounted stream of $\pi(i)$ equals the fixed cost, $P_{n}$. With an assumption of perfect foresight, the following zero-profit condition holds at every point in time:

$$
\int_{t}^{\infty} e^{-r(z-t)} \pi(i, z) d z=P_{n}(t),
$$

which, by taking the derivative with respect to time, implies:

$$
P_{n} r=\pi(i)+\dot{P}_{n}
$$

Using equation (2), this can be rewritten as follows;

$$
\pi=\frac{W_{n}}{\delta N}\left(r-\frac{\dot{W}_{n}}{W_{n}}+\frac{\dot{N}}{N}\right) .
$$

These structure of our model leads to a symmetric monopolistic-competition equilibrium; that is, all $S(i)$ 's and all $P_{s}(i)$ 's are the same across $i$. Thus, we can rewrite equations (6), (7) and (9) as follows (we delete index $i$ from equations):

$$
\begin{aligned}
& X=N^{\frac{1}{\beta}} S, \\
& P_{s}=N^{\frac{1}{\beta}-1}, \\
& W_{s}=\beta N^{\frac{1}{\beta}-1} .
\end{aligned}
$$

Thus, equation ( 8 ) becomes

$$
\pi=(1-\beta) N^{\frac{1}{\beta}-1} S,
$$


From equations (14) and (15), we obtain:

$$
S=\frac{\beta \pi}{(1-\beta) W_{s}}
$$

Recalling that one unit of labor produces one unit of $S$ and that there are $N$ varieties, the labor employment in the intermediate-good sector, $L_{s}$, is:

$$
L_{s}=S N
$$

Thus, from equations (12) and (17), the production function of good $X$ is reduced to:

$$
X=N^{\frac{1}{\beta}-1} L_{s} .
$$

We assume full employment of labor and free mobility of labor across sectors. Then, from equations (2), (4) and (14), the following equations hold in an interior equilibrium:

$$
\begin{aligned}
& W_{y}=P f^{\prime}=W_{s}=\beta N^{\frac{1}{\beta}-1}=W_{n}=P_{n} \delta N \equiv W, \\
& L_{y}+L_{s}+L_{n}=1 .
\end{aligned}
$$

Appendix A shows that the following equation is obtained in an interior equilibrium: ${ }^{12}$

$$
L_{s}=\frac{\beta r}{\delta(1-\beta)}-\frac{1-2 \beta}{1-\beta} L_{n} .
$$

Thus, changes in the labor allocation between the $R \& D$ sector and the intermediate-good sector crucially depend upon the value of $\beta$. Substituting equation (20) into (21), we derive:

$$
1-L_{y}=\frac{\beta r}{\delta(1-\beta)}+\frac{\beta}{1-\beta} L_{n},
$$

which shows that $L_{y}$ and $L_{n}$ are negatively correlated. From equation (21) and (22), we find that if $0<\beta<1 / 2$ and if $L_{y}$ decreases, $L_{n}$ rises while $L_{v}$ falls. It should be noted, however, that the economy with $L_{n}>0$ and $L_{s}=0$ cannot be supported because there is no demand for R\&D with $L_{s}=0$. Appendix B shows that if $0<\beta \leq \delta /(r+2 \delta), L$, can be zero at some point in time. Thus, in the following analysis, we focus on the case where $\delta /(r+2 \delta)<\beta<1$

\footnotetext{
${ }^{12}$ In the following analysis, we assume that $\beta r / \delta(1-\beta)<1$.
} 
If the SOE produces $X, Y$, and know-how under free trade, we can solve for $L_{y}, L_{s}$, and $L_{n}$, and thus $X, Y$, and $\dot{N}$ from $P=P^{*}$ and equations (19-21). We summarize the above argument in the following lemma;

Lemma 1 As the labor employment in the $Y$ sector falls, the labor employment in the R\&D sector necessarily rises and the labor employment in the intermediate good sector rises with $1 / 2<\beta<1$, is constant with $\beta=1 / 2$, and falls with $\delta /(r+2 \delta)<\beta<1 / 2$.

Moreover, equation (21) leads to

Lemma 2 With equation (19) and $L_{n}=0$, the labor allocation to the intermediate good sector is $L_{s}=\beta r / \delta(1-\beta)$, which is independent of the value of $N$ and constant.

\section{Economic Growth in a Small Open Economy}

In this section, we analyze the patterns of economic growth and the evolution of the sectoral composition of output in the development process. We assume that, at time $t=0$, a SOE is established with $N(0)$. Factor income (FI), which consists of wage income and the rent on land, in terms of the final good, is used as an index of economic growth. ${ }^{13}$ Since the prices of final goods (consumption goods) are exogenously given and fixed for the SOE, it is obvious that economic welfare improves as FI increases. From equations (4) and (5), FI in terms of good $Y, I_{y}$, is given by:

$$
I_{y}=\left(1-L_{y}\right) f^{\prime}\left(L_{y}\right)+f\left(L_{y}\right) \text {. }
$$

Differentiating this equation with respect to $L_{y}$, we obtain:

$$
\frac{d I_{y}}{d L_{y}}=\left(1-L_{y}\right) f^{\prime \prime}\left(L_{y}\right)<0, \quad \text { for } 0<L_{y}<1 .
$$

Thus, we obtain an important result:

Lemma 3 FI in terms of final goods increases as the labor employment in the Y sector falls.

\footnotetext{
${ }^{13}$ If GNP is used as an index of economic growth, preference structure has to be specified to determine the amount of saving and hence interest revenue from the capital market. In order to highlight the contribution of technological progress to economic growth, we focus on FI.
} 
This lemma tells us that changes in the labor allocation are closely related to economic growth and that we can analyze economic growth by examining the labor allocation to the $Y$ sector.

The following task is to find the location of a production equilibrium on the production possibility frontier (PPF) and examine changes in the labor allocation among sectors. With a given value of $N$, we can construct the PPF among $X, Y$, and new know-how $(\dot{N})$ from equations (1), (3), (18) and (20). The marginal product of labor in the production of both good $X$ and know-how is constant, while that in the production of good $Y$ is diminishing. Thus, the PPF on both the X-Y plane and the Y- $\dot{N}$ plane is strictly concave to the origin, while the PPF on the X- $\dot{N}$ plane is linear. Figure 1 shows the PPF.

For the following arguments, it is convenient to use its projection on the X-Y plane, which is shown in Figure 2. Noting Lemma 2, suppose that in Figure 2, $X=O D_{1}=$ $(\beta r / \delta(1-\beta)) N^{\frac{1}{\beta}-1}$, that is, point $B$ is a production point where both equation (19) and $L_{n}=0$ hold. Then, from Lemma 1 , we see that 1 ) if $\beta=1 / 2$, an interior equilibrium is located on $\left.B D_{1}, 2\right)$ if $1 / 2<\beta<1$, it is located on the locus such as $B D_{2}$, and 3) if $\delta /(r+2 \delta)<\beta<1 / 2$, it is located on the locus such as $B D_{3}$. Since there is no labor allocation to the $\mathrm{R} \& \mathrm{D}$ sector at point $B$, the labor corresponding to $M A$ in terms of good $Y$ equals the labor employed by the intermediate-good sector. As the labor employment in the $Y$ sector falls, a production point moves towards point $D_{i}(i=1,2,3)$ on $B D_{i}$. At point $E_{1}$, for example, the labor corresponding to $M A, A E$, and $E O$ in terms of $\operatorname{good} Y$ is, respectively, allocated to the intermediate good sector, the R\&D sector, and the $Y$ sector. ${ }^{14}$ Suppose that the value of $N$ increases and the new PPF is given by $M H^{\prime}$ in Figure 2. Then point $B$ moves horizontally to $B^{\prime}$ because the labor allocation to the intermediate-good sector with $L_{n}=0$ is independent of $N$ and constant (recall Lemma 2). $B D_{i}$ also shifts out proportionally (i.e., $B B^{\prime} / A B=D_{i} D_{i}^{\prime} / O D_{i}$ ).

\footnotetext{
${ }^{14}$ Note that, at point $E_{2}\left(E_{3}\right)$, the labor corresponding to more (less) than $M A$ in terms of good $Y$ is allocated to the intermediate-good sector and the labor corresponding to $E O$ is allocated to the $Y$ sector.
} 
In order to see both changes in the labor allocation to the $Y$ sector and the location of a production equilibrium, one must consider the producer price, $P$, which is given by equation (19):

$$
P=\frac{\beta N^{\frac{1}{\beta}-1}}{f^{\prime}\left(L_{y}\right)}
$$

This is a key equation and leads to the following three lemmas that are useful for the following arguments. The first two lemmas are trivial from equation (25):

Lemma 4 With a given value of $N$, the producer price monotonically falls as the labor employment in the $Y$ sector falls.

Thus, on $B D_{i}(M J)$ in Figure 2, the producer price is the highest at $B(M)$ and it falls and approaches zero as the production point moves towards $D_{i}(J)$.

Lemma 5 With a given labor employment in the $Y$ sector, the producer price rises as the value of $N$ increases.

Thus, the producer prices at $M$ and $B$ increase as the value of $N$ increases or as $B D_{i}$ shifts to the right in Figure 2. That is, the producer price at $B^{\prime}$ is higher than the producer price at $B$ and the producer price at $M$ with the PPF, $M H^{\prime}$, is higher than the producer price at $M$ with the PPF, $M H$.

Substituting a free trade equilibrium condition, $P^{*}=P$, into equation (25), we obtain the third lemma:

Lemma 6 With a free trade equilibrium, the labor allocation to the $Y$ sector falls and the labor allocation to the R\&D sector rises as the value of $N$ increases.

This is because the intermediate-good and the R\&D sectors can offer a higher wage as the value of $N$ rises [see equation (19)]. Thus, labor leaves the $Y$ sector. This implies that if there is positive $R \& D$ activity with a given technology level, there will be more $R \& D$ with a higher technology level.

Lemmas 3 and 6 lead to the following proposition; 
Proposition 1 Different technology levels (i.e., different values of $N$ ) result in different levels of FI under free trade. FI increases as the value of $N$ increases.

Next we derive the following lemma with respect to the location of the production equilibrium;

Lemma 7 Suppose that the PPF on the $X-Y$ plane is given by $M H$ in Figure 2. Then, the production equilibrium is located on $M B D_{i}$ (except at $D_{i}$ ).

Noting that $P^{*}$ is given, we confirm the following three possibilities with respect to the production of $X$ and $Y$ in equilibrium: 1) $P^{*}=P$ and positive production of both $X$ and $Y$, 2) $P^{*} \geq P$ and no production of $X$, and 3) $P^{*} \leq P$ and no production of $Y$. It is easy to verify that the third case is not possible. Suppose that $Y=0$. Then $L_{y}=0$ and thus $P$ is zero from equation (25). This contradicts $0<P^{*} \leq P$. The second case with positive production of know-how is not possible, either. In the second case, since there is no production of $X$, there is no demand for intermediate goods and hence no R\&D activity. Thus, complete specialization in good $Y$ is the only possible equilibrium in the second case.

The first case will now be considered. As we have seen, an interior production equilibrium is located on $B D_{i}$ (except at $D_{i}$ ) in Figure 2. Thus, we have only to determine if a point between $M$ and $H$ (except $B$ ) is consistent with the equilibrium conditions. By comparing such a point with point $B$, it can be shown that a production point between $M$ and $B$ is consistent with the equilibrium conditions, while a production point between $B$ and $H$ is not. We consider points $K$ and $I$ as examples. At point $K(I)$, the output of good $X$ and thus the output of each intermediate good, $S$, are less (greater) than that at point $B$. This implies from equation (15) that the profit, $\pi$, is smaller (greater) at $K(I)$ than at $B$ over time, and in turn from equation (10) that $P_{n}$ is lower (higher) at $K(I)$ than at $B$. Thus, noting that $W_{s}=W_{n}$ at $B$, we immediately see from equation (19) that $W_{s}>W_{n}$ $\left(W_{0}<W_{n}\right)$ at $K(I)$, which is consistent (inconsistent) with no R\&D activity.

We are now ready to determine the location of the production equilibrium and to establish growth paths. The production equilibrium is located on $M B D_{i}$ where the supply price equals 
the world price. Lemma 4 implies that the world price uniquely determines the production equilibrium point. In an equilibrium on $M B$, there is no labor allocation to.the R\&D sector and the technology level is constant over time. Thus, the labor allocation between the $Y$ sector and the intermediate good sector is invariable and the sectoral composition of output and FI are constant over time. It should be noted, however, that the level of FI depends on the location of the equilibrium, and that even if both final goods are produced, there is no economic growth.

In an equilibrium between $B$ and $D_{i}$, on the other hand, economic growth is generated by the increase in the value of $N$. Suppose that $\beta=1 / 2, O D_{1}=(\beta r / \delta(1-\beta)) N(0)^{\frac{1}{\beta}-1}$, and $P^{*}=P$ at point $E_{1}$ in Figure 2. Then, $E_{1}$ is the equilibrium at $t=0$. Since the labor corresponding to $B E_{1}$ in terms of good $Y$ is allocated to the R\&D sector, the value of $N$ will be higher or $B D_{1}$ will shift to the right as time passes. Thus, Lemmas 3 and 6 confirm that the labor employment in the $Y$ sector falls but the labor employment in the R\&D sector and FI increases over time.

Since the labor employment in the $Y$ sector decreases, the output of good $Y$ decreases. Whether or not the output of good $X$ increases in the process of economic growth depends on the value of $\beta$ and the functional form $f($.$) . It is obvious from Lemma 1$ and equation (18) that the output of good $X$ increases if $1 / 2 \leq \beta<1$. However, if $\delta /(r+2 \delta)<\beta<1 / 2$, the output of good $X$ may decrease because the labor allocation to the intermediate-good sector decreases. Appendix $\mathrm{C}$ derives a necessary and sufficient condition under which the output of good $X$ increases. The condition is

$$
\frac{f^{\prime \prime}}{f^{\prime}} L_{s}<\frac{2 \beta-1}{\beta} \text {. }
$$

Since the left hand side is negative, we confirm that this condition always holds if $1 / 2 \leq$ $\beta<1$. If this condition holds, in Figure 2 changes in the sectoral composition of output, or growth path, induced by the increase in the value of $N$ can be shown by a locus such as $E_{1} Z$.

The location of the production equilibrium and the growth dynamics depend on the value of the world price, $P^{*}$, relative to the producer prices at $B$ and $M, P_{B}$ and $P_{M}$, at $t=0$. In 
fact, this corresponds to the technology level at $t=0, N(0)$, relative to the two "critical" technology levels, $\bar{N}$ and $\hat{N} . \bar{N}$ and $\hat{N}$ are, respectively, defined as the technology level such that the producer price at $B$ equals the world price and the technology level such that producer price at $M$ equals the world price, i.e.,

$$
\begin{aligned}
& \bar{N} \equiv\left[\frac{P^{\star} f^{\prime}\left(1-\frac{\beta r}{\delta(1-\beta)}\right)}{\beta}\right]^{\frac{\beta}{1-\beta}}, \\
& \hat{N} \equiv\left[\frac{P^{\star} f^{\prime}(1)}{\beta}\right]^{\frac{\beta}{1-\beta}}
\end{aligned}
$$

Thus, noting Lemma 5 , we see that 1 ) if $N(0) \leq \hat{N}$, then $P^{*} \geq P_{M}$ and hence the equilibrium is at $M, 2)$ if $\hat{N}<N(0)<\bar{N}$, then $P_{B}<P^{*}<P_{M}$ and hence the equilibrium is located between $M$ and $B, 3)$ if $N(0)=\bar{N}$, then the equilibrium is at $B$, and 4) if $N(0)>\bar{N}$, then $P^{*}<P_{B}$ and hence the equilibrium is located between $B$ and $D_{i}$.

The above analysis is summarized in the following two propositions:

Proposition 2 If $N(0) \leq \hat{N}$, the economy completely specializes in good $Y$ and $F I$ is constant over time. If $\dot{N}<N(0) \leq \bar{N}$, the economy produces intermediate goods and final goods but $F I$ is constant. If $N(0)>\bar{N}$, the economy engages in all productive activities and $F I$ increases over time.

Proposition 3 If $N(0) \leq \bar{N}$, neither the labor allocation to each sector nor the sectoral composition of output changes over time. If $N(0)>\bar{N}$, the labor force is reallocated from the $Y$ sector to the RED and the intermediate-good sectors. The variety of intermediate goods increases, the output of good $Y$ decreases, and the output of good $X$ increases under equation (26).

As we have seen above, FI increases if the value of $N$ rises. When economic growth is studied, not only economic growth itself but also the growth rate often becomes a subject of discussion. We now examine changes in the growth rate of FI. We define $g \equiv \dot{I}_{y} / I_{y}$ and examine the sign of $\dot{g}$. First, note that 


$$
\dot{I}_{y}=\frac{d I_{y}}{d L_{y}} \frac{d L_{y}}{d t}
$$

From equation (25) under free trade, we obtain

$$
\frac{d L_{y}}{d t}=\frac{1}{f^{\prime \prime} P^{*}}\left[\delta(1-\beta) L_{n} N^{\frac{1}{\beta}-1}\right]<0
$$

Substituting equations (19), (24) and (28) into equation (27), we obtain

$$
g=\frac{\dot{I}_{y}}{I_{y}}=\frac{\delta(1-\beta)}{\beta} \frac{\left(1-L_{y}\right) L_{n} f^{\prime}}{\left(1-L_{y}\right) f^{\prime}+f} .
$$

Then, differentiating this equation with respect to $L_{y}$, we obtain:

$$
\frac{d g}{d L_{y}}=\frac{\delta(1-\beta)}{\beta} \frac{\left[-L_{n}+\left(1-L_{y}\right) \frac{d L_{n}}{d L_{y}}\right] f^{\prime}\left[\left(1-L_{y}\right) f^{\prime}+f\right]+\left(1-L_{y}\right) L_{n} f^{\prime \prime} f}{\left[\left(1-L_{y}\right) f^{\prime}+f\right]^{2}}<0 .
$$

Thus, $\dot{g}>0$ always holds because $\dot{g}=\left(d g / d L_{y}\right)\left(d L_{y} / d t\right)$.

However, there is an upper bound of the growth rate. To see this, we rewrite equation (29) as follows:

$$
g=\left[\frac{\delta(1-\beta)}{\beta}\right]\left[\frac{\left(1-L_{y}\right) L_{n}}{\left(1-L_{y}\right)+f / f^{\prime}}\right]
$$

In the process of economic growth, $L_{y}$ approaches zero. As $L_{y}$ approaches zero, $f$ and $f^{\prime}$, respectively, approach zero and infinite. Thus, in the second term of the right hand side, the denominator approaches 1 , while the numerator approaches the limit value of $L_{n}$. Since $L_{n}$ is bounded from above by $1, g$ is also bounded from above. If $\beta=1 / 2$, for example, the limit value of $L_{n}$ is $1-r / \delta$ (recall Lemma 2) and hence the growth rate approaches $\delta-r$. Thus, the following proposition is obtained;

Proposition 4 The growth rate of FI increases in the process of economic growth. However, there exists an upper bound of the growth rate.

\section{Policy Analysis under a Zero-Growth Equilibrium}

An interpretation of an equilibrium on $M B$ in Figure 2 is that the economy is trapped at a low-level (zero-growth) equilibrium because of a low initial technology level. Thus, a solution 
to avoid this low-level equilibrium is the accumulation of technology. However, no private sector agent has an incentive to increase the technology level. Thus, a policy is needed to start the accumulation of technology. Several policies such as taxes, subsidies, and tariffs are possible. In this section, we specifically examine a production tax on the $Y$ sector and a wage subsidy to the $R \& D$ sector. With the aid of figures, ${ }^{15}$ it is shown that temporary use of these policies can be made to initiate economic growth. ${ }^{16}$ The effects of an exogenous increase in the labor force is also examined.

\subsection{A Production Tax on the Y Sector}

We assume that the government imposes a production tax on the $Y$ sector at time $t$. The imposition of the tax modifies equation (19) as follows:

$$
W_{y}=\frac{P}{1+\tau} f^{\prime}=W_{s}=\beta N^{\frac{1}{\beta}-1},
$$

where $\tau$ is a tax rate. Noting that the value of $N$ is not affected by the tax at time $t$ and that $P=P^{*}$, we see that some labor must be released from the $Y$ sector to other sector(s). If some labor is allocated to the $\mathrm{R} \& \mathrm{D}$ sector, economic growth begins. This is shown in Figure 3 as follows. Suppose that the economy is initially located at point $K$ and $O D=(\beta r / \delta(1-\beta)) N(0)^{\frac{1}{\beta}-1}$. First note that the imposition of the tax does not affect equation (21). Thus, the equilibrium must be located on $M B D$ even if the tax.is imposed. Suppose that the government picks a tax rate, $\tau$, such that $P^{*} /(1+\tau)<P$ at $B$ holds, for example, $P^{*} /(1+\tau)=P$ at $E_{t}$ (recall Lemma 4 ). Then the tax shifts the equilibrium from point $K$ to point $E_{t}$ by reallocating some labor from the $Y$ sector to the other two sectors. ${ }^{17}$ Since the value of $N$ increases, the output of good $Y$ decreases and the output of good $X$ increases. In Figure 3, changes in the sectoral composition of output are shown by $E_{t} E_{t}^{\prime}$ extended. Suppose that the PPF, $M H^{\prime}$, is drawn under the assumption that $N=\bar{N}$, that

\footnotetext{
${ }^{15}$ Although Figures 3,4 and 5 are drawn with $\beta=1 / 2$, the essential arguments do not change with $\beta \neq 1 / 2$.

${ }^{16}$ We assume that a tax is redistributed in a lump-sum manner and that a subsidy is financed by lump-sum taxation.

${ }^{17}$ If $P^{*} /(1+\tau) \geq P$ at $B$, the equilibrium with the $\operatorname{tax}$ is located on $K B$ and economic growth is not generated.
} 
is, that $P^{\times}=P$ at point $B^{\prime}$ (recall Lemma 5). Then, once the increase in the value of $N$ shifts $B D(M H)$ to the right of $B^{\prime} D^{\prime}\left(M H^{\prime}\right)$, the economy will no longer need the tax. By removing the tax, the economy will be in a situation such that $\bar{N}<N$. Thus, technology accumulates even without the tax. If the government removes the tax immediately after point $E_{t}^{\prime}$ (where the growth path with the tax intersects $B^{\prime} D^{\prime}$ ) had been reached, then it will jump to the growth path, $B^{\prime} Z^{\prime}$.

\subsection{A Wage Subsidy to the R\&D Sector}

We assume that the government introduces a wage subsidy to the R\&D sector at time $t$. The subsidy modifies equations (19) and (21) as follows:

$$
\begin{aligned}
& W_{y}=P f^{\prime}=W_{s}=\beta N^{\frac{1}{\beta}-1}=W_{n}(1+s)=\delta N P_{n}(1+s), \\
& L_{s}=\frac{\beta r}{\delta(1-\beta)(1+s)}-\frac{1-2 \beta}{1-\beta} L_{n},
\end{aligned}
$$

where $s$ is a subsidy rate. These equations imply that the subsidy reallocates some labor from the intermediate-good sector to the R\&D sector and hence economic growth commences. This is shown in Figure 4. Suppose that a free trade equilibrium is initially located between $M$ and $B$, say, at $K .^{18}$

We know that $W_{s}>\delta N P_{n}=W_{n}$ at $K$. We assume that the government chooses a subsidy rate, $s$, such that $W_{s}=\delta N P_{n}(1+s)=W_{n}(1+s)$. There is no immediate impact of the subsidy on $N(t)$. From equation (25), this implies that the labor employment in the $Y$ sector is the same as initially. Thus, the subsidy reallocates some labor from the intermediate-good sector to the R\&D sector. Suppose that the subsidy decreases the output of good $X$ by $L L^{\prime}$. Then, the production equilibrium moves from $K$ to $E_{s}$. That is, $K^{\prime} E_{s}$ units of labor in terms of good $Y$ are reallocated from the intermediate-good sector to the R\&D sector and $M A^{\prime}$ units of labor in terms of good $Y$ remain in the intermediate-good sector. Thus, changes in the sectoral composition of output under the subsidy is shown by

\footnotetext{
${ }^{18}$ At point $M$, the argument presented here does not hold because the world price is so high that there is no production of good $X$ and no demand for know-how.
} 
$E_{s} E_{s}^{\prime}$ extended. However, once technology is accumulated up to the level of $\bar{N}$, the economy will no longer need the subsidy to generate economic growth. Suppose that $M H^{\prime}$ is drawn under the assumption that $N=\bar{N}$, that is, that $P^{*}=P$ at point $B^{\prime}$. Then, $N=\bar{N}$ holds when the production of good $X$ with the subsidy reaches $O L^{\prime \prime}$. Thus, if the government removes the subsidy immediately after point $E_{s}^{\prime}$ (where the growth path with the subsidy intersects $K^{\prime \prime} L^{\prime \prime}$ ) has been reached, then the economy will move to the growth path, $B^{\prime} Z^{\prime}$.

We thus obtain the following proposition:

Proposition 5 If the economy is trapped at a low-level (zero-growth) equilibrium because of an insufficient technology level, there are general simple policies that can used to initiate $R \& D ; R \& D$, in turn, can initiate economic growth. Such policies could be temporary.

It is worthwhile noting that although they can initiate growth, the.production tax on the $Y$ sector and the wage subsidy to the R\&D sector, respectively, result in a different reallocation of labor at time $t$. The production tax reallocates some labor from the $Y$ sector to the other two sectors, while the wage subsidy reallocates some labor from the intermediate-good sector to the $R \& D$ sector.

In our model, there exist two distortions: externalities in $R \& D$ and monopolistic competition in the intermediate-good market. In the $R \& D$ sector, producers fail to take account of knowledge creation which increases the productivity of R\&D. From the social-optimum point of view, the R\&D activity should be encouraged. Monopolistic competition also leads to less output of each intermediate good from the social-optimum point of view. Thus, the wage subsidy to the $R \& D$ sector enlarges the distortion from monopolistic competition, while the production tax on the $Y$ sector can decrease both distortions. It should be emphasized, however, that the government needs permanent policies in order to attain the first-best equilibrium.

\subsection{An Exogenous Increase in the Labor Force}

Next we consider the effect of an exogenous increase in the labor force. Suppose that the labor force increases by $\Delta L$ at time $t$. Then both $\bar{N}$ and $\hat{N}$ are modified as follows: 


$$
\begin{aligned}
& \bar{N} \equiv\left[\frac{P^{*} f^{\prime}\left(1+\Delta L-\frac{\beta r}{\delta(1-\beta)}\right)}{\beta}\right]^{\frac{\beta}{1-\beta}}, \\
& \hat{N} \equiv\left[\frac{P^{*} f^{\prime}(1+\Delta L)}{\beta}\right]^{\frac{\beta}{1-\beta}}
\end{aligned}
$$

It is obvious that both $\bar{N}$ and $\hat{N}$ decrease as $\Delta L$ increases. Thus a sufficiently large increase in the labor force initiates economic growth.

This can be shown in Figure 5. Suppose that the PPF on the X-Y plane shifts from $M H$ to $M^{\prime} H^{\prime}$ in Figure $5 .{ }^{19}$ First, note that even if the labor force increases, equation (21) does not change and hence Lemma 2 still holds. Thus, the production equilibrium must be located on $M^{\prime} B^{\prime} D$. However, it can be seen from equation (19) that the increase in the labor force has no immediate impact on the labor employment in the $Y$ sector. Thus, if the economy is initially at point $K$, the increase in the labor force shifts the equilibrium from $K$ to $K^{\prime}$. At $K^{\prime}$, the labor corresponding to $B^{\prime} K^{\prime}$ in terms of good $Y$ is newly allocated to the $R \& D$ sector and hence economic growth begins.

Since there is no change in the labor allocation to the $Y$ sector at time $t$, neither the wage rate nor the rental rate changes at time $t$. Thus, if the labor force is proportional to population, per capita FI falls at time $t$. However, if the increase in the labor force is once and for all, economic growth will eventually result in an increase in per capita FI, beyond its initial level. If, on the other hand, the increase in the labor force is continuous (say, continuous population growth), the increase in the labor force has two opposite affects on economic growth: first, it decreases per capita FI and second, it accelerates the accumulation of technology. Thus, even if technology is accumulating, per capita FI may decrease.

The above analysis leads to:

Proposition 6 An exogenous increase in the labor force under a zero-growth equilibrium may initiate economic growth. At the time of the increase, neither the wage rate nor the rental changes, and per capita FI decreases.

\footnotetext{
${ }^{19}$ An exogenous increase in the labor force shifts the PPF outwards and the shift is biased for good $X$.
} 


\section{Concluding Remarks}

The patterns of economic growth for a multi-sector, SOE have been analyzed. Key points

are that augmentation of the technology level through R\&D generates economic growth, and that changes in the technology level are endogenously determined because the labor allocation to the $R \& D$ sector is endogenous.

Whether or not the technology level rises under free trade depends on its initial level. A sufficiently high initial level of technology leads to a self-made process. of technology accumulation and thus continuous economic growth. In this case, not only the economy grows but also the growth rate increases over time. Dynamic IRS play an important role in this result. An insufficient initial level of technology, on the other hand, cannot lead to any accumulation under free trade and thus the economy is trapped at a low-level (zerogrowth) equilibrium over time. It should be emphasized that even if both final goods are produced, zero growth is possible, and that different technology levels lead to different levels of FI. These results capture the observed diversity across countries in both levels and rates of growth of per capita income.

Two critical technology levels have been defined to determine whether or not an initial technology level is sufficient. It should be noted that critical technology levels depend on the world price, $P^{*}$, and the world instantaneous interest rate, $r$. It is easy to see that both critical technology levels rise as the world price of good $Y$ rises and that the critical technology level, $\bar{N}$, rises as the world instantaneous interest rate rises. Thus, any exogenous changes in those parameters will affect economic growth.

If the initial technology level is not sufficient to generate economic growth, the government can initiate economic growth by imposing a temporary policy to create technology accumulation. Although there exist dynamic IRS associated with the technology accumulation, they are purely external. Thus, no private agent has an incentive to increase the technology level in a zero-growth equilibrium. The economy without a sufficient initial level of technology cannot enjoy dynamic externalities. Therefore, government intervention to 
capture dynamic externalities may be justified. We have considered two temporary policies: a production tax on the $Y$ sector and a wage subsidy to the R\&D sector. It has also been shown that an exogenous increase in the labor endowment can solve the zero-growth problem.

Even if the technology is accumulated without any intervention, monopolistic competition results in less output of each intermediate good than would be required from the socialoptimum point of view. Externalities in R\&D also lead to less R\&D activity than would be required from the social-optimum point of view. Thus, permanent intervention by the government can also be justified. However, the exact nature of such policies has not been analyzed in this paper.

Changes in the labor allocation among sectors are closely related to the evolution of the sectoral composition of output and economic growth. In the process of economic growth, it has been shown that some labor necessarily shifts from the $Y$ sector to the R\&D sector. Since the $Y$ sector releases labor at increasing marginal costs, FI increases in our model. Changes in the labor allocation to the intermediate-good sector crucially depend on the value of $\beta$, the parameter representing the elasticity of substitution in the production of good $X$. This is because, as the variety of intermediate goods increases, the size of $\beta$ affects the degree of monopoly power of each intermediate-good producer ${ }^{20}$ With increases in the variety, the larger the value of $\beta$ is, the more quickly he/she loses the monopoly power. Thus, more of each intermediate good is produced, which implies more labor is allocated to the intermediate-good sector.

As in Grossman and Helpman (1989a), it is possible to allow for the diffusion of knowledge created in R\&D from the rest of the world (ROW). Knowledge can diffuse through publications, conferences, personal contact etc. In the presence of knowledge diffusion from the ROW, economic growth can be magnified by increasing the productivity in R\&D. Even if the economy is initially in a zero-growth equilibrium, knowledge diffusion can initiate economic growth in the future.

\footnotetext{
${ }^{20}$ The size of $\beta$ also affects the price of each intermediate good through equation (13).
} 


\section{Appendix A}

In this appendix, we derive equation (21) from equations (1), (11), (16), (17) and (19).

From equation (19), we obtain

$$
\frac{\dot{W}}{W}=\frac{1-\beta}{\beta} \frac{\dot{N}}{N}
$$

Substituting this equation into equation (11) and using equation (1), we obtain

$$
\pi=\frac{W}{\delta N}\left(r-\frac{1-2 \beta}{\beta} \frac{\dot{N}}{N}\right)=\frac{W}{\delta N}\left[r-\frac{(1-2 \beta) \delta}{\beta} L_{n}\right] .
$$

Substituting this equation into equation (16), we obtain

$$
S=\frac{\beta}{\delta N(1-\beta)}\left[r-\frac{(1-2 \beta) \delta}{\beta} L_{n}\right] .
$$

Substituting this equation into equation (17), we obtain equation (21).

\section{Appendix B}

This appendix shows that if $0<\beta<\delta /(r+2 \delta), L$, becomes zero at some point in time in the process of economic growth. We substitute $L_{s}=0$ into equation (21) to obtain

$$
L_{n}=\frac{\beta r}{\delta(1-2 \beta)} .
$$

If $L_{n}$ is less than the labor endowment $(=1)$ with $L_{s}=0, L_{s}=0$ holds at some point in time in the process of economic growth. Thus, we obtain the result. 


\section{Appendix C}

This appendix derives a necessary and sufficient condition under which the output of good $X$ increases in the process of economic growth. From equation (18), we know that the output of good $X$ increases in the process of economic growth if and only if

$$
\frac{d \ln X}{d t}=\frac{1-\beta}{\beta} \frac{\dot{N}}{N}+\frac{\dot{L}_{a}}{L_{s}}>0 .
$$

From equations (20) and (21), we obtain

$$
L_{s}=\frac{r}{\delta}+\frac{2 \beta-1}{\beta}\left(1-L_{y}\right) \text {. }
$$

Thus,

$$
\dot{L}_{s}=\frac{1-2 \beta}{\beta} \dot{L}_{y}
$$

Substituting equation (28) into this equation and noting equations (1) and (19), we obtain

$$
\dot{L}_{s}=\frac{(1-2 \beta)(1-\beta) f^{\prime} \dot{N}}{\beta^{2} f^{\prime \prime} N} .
$$

Substituting this equation into equation (30), we obtain

$$
\frac{d l n X}{d t}=\frac{1-\beta}{\beta} \frac{\dot{N}}{N}\left(1+\frac{(1-2 \beta) f^{\prime}}{\beta f^{\prime \prime} L_{s}}\right)>0 .
$$

This condition is equivalent to

$$
\frac{f^{\prime \prime}}{f^{\prime}} L_{s}<\frac{2 \beta-1}{\beta} \text {. }
$$




\section{References}

Chenery, H.,, 1960, Patterns of industrial growth, American Economic Review 50, 649-653.

Dixit, A., and J. E. Stiglitz, 1977, Monopolistic competition and optimum product diversity, American Economic Review 67, 297-308.

Ethier, W. J., 1982, National and international returns to scale in the modern theory of international trade, American Economic Review 72, 389-405.

Findlay, R., 1984, Growth and development in trade models, in R.Jones and P. Kenen (eds.), Handbook of International Economics, (North Holland, Amsterdam), 185-236.

Grossman, G. M., and E. Helpman, 1989a, Comparative advantage and long-run growth, NBER working paper, no.2809.

Grossman, G. M., and E. Helpman, 1989b, Growth and welfare in a small open economy, NBER working paper, no.2970.

Jensen, R and M. Thursby, 1986, A strategic approach to product life cycle, Journal of International Economics 21, 269-284.

Kuznets, S., 1957, Quantitative aspects of the economic growth of nations: II. industrial distribution of national product and labor force, Economic Development and Cultural Change 5 supplement, 2-111.

Lucas, R. E. Jr., 1988, On the mechanics of economic development, Journal of Monetary Economics 22, 1-42.

Manning, R., 1982, Trade, education and economic growth: The small open economy case, International Economic Review 23, 83-106.

Markusen, J. R., 1988, Production, trade, and migration with differentiated, skilled workers, Canadian Journal of Economics 21, 492-506.

Markusen, J. R., 1989, Trade in producer services and in other specialized intermediate inputs, American Economic Review 79, 85-95.

Matsuyama, K., 1989, Increasing returns, industrialization and indeterminacy of equilibrium, unpublished manuscript, June (Northwestern University).

Murphy K. M., A. Shleifer, R. W. Vishny, 1989, Industrialization and the big push, Journal of Political Economics 97, 1003-1026.

Okuno-Fujiwara, M., 1988, Interdependence of industries, coordination failure and strategic promotion of an industry, Journal of International Economics 25, 25-43.

Romer, P. M., 1986, Increasing returns and long run growth, Journal of Political Economy 94, 1002-1037.

Romer, P. M., 1988, Endogenous technological changes, Paper presented at the SUNYBuffalo Conference on 'The Problem of Development'.

Schmitz, J., 1987, Optimal growth and product innovation, University of Wisconsin Working Paper. 
Smith, A., 1984, Capital theory and trade theory, in R. Jones and P. Kenen (eds.), Handbook of International Economics, (North Holland, Amsterdam), 289-324. 


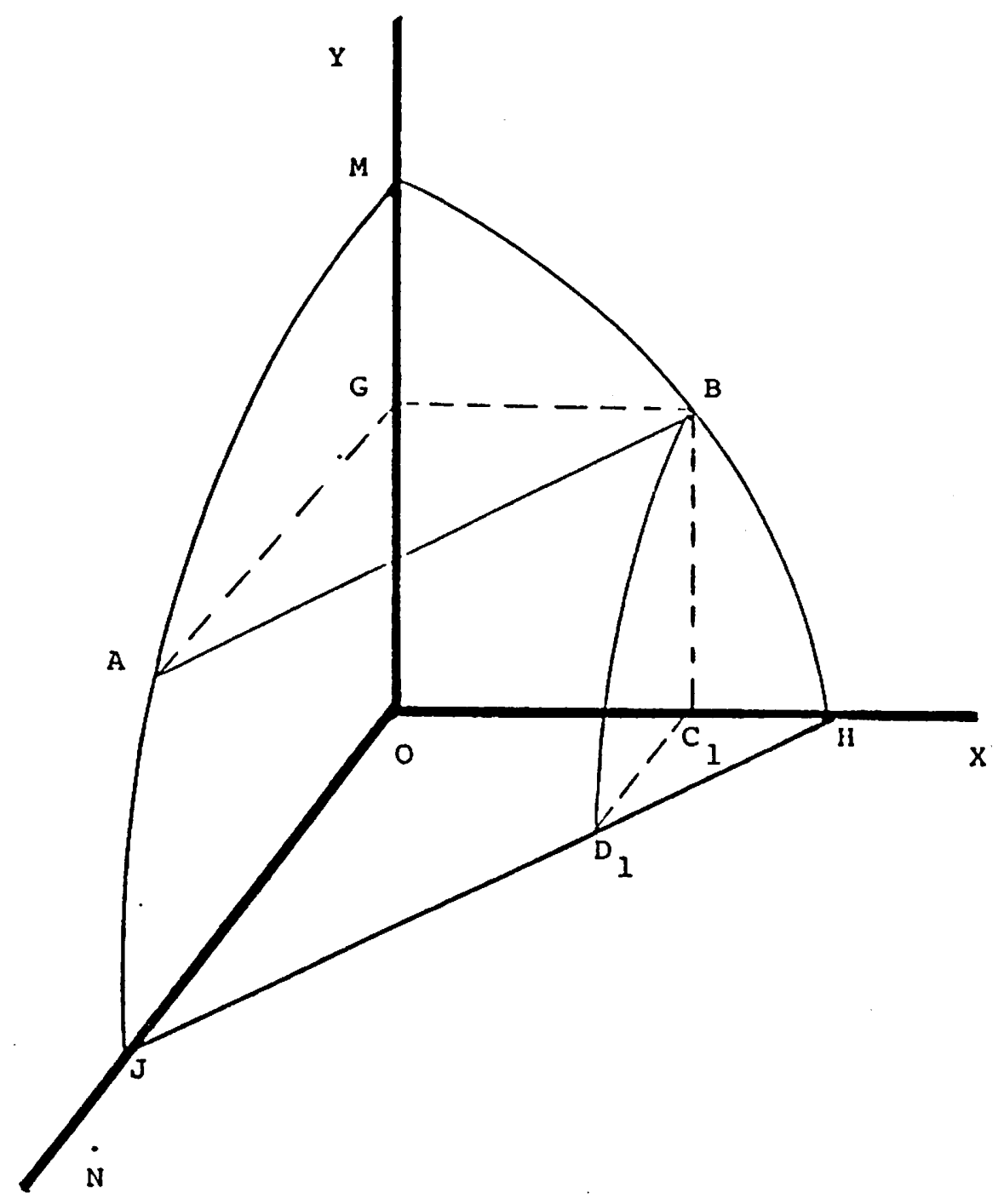

Figure l 


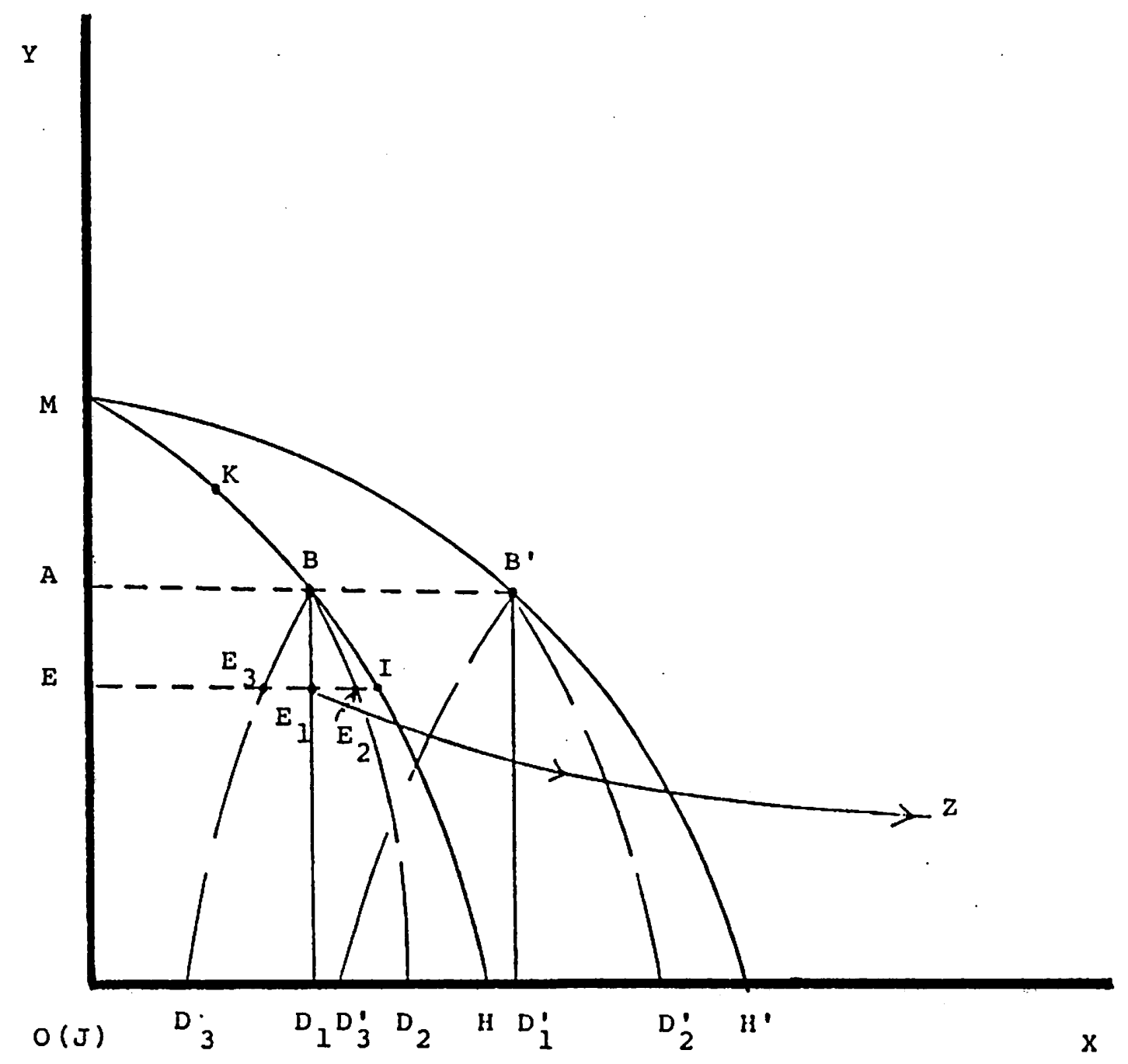

Figure

2 


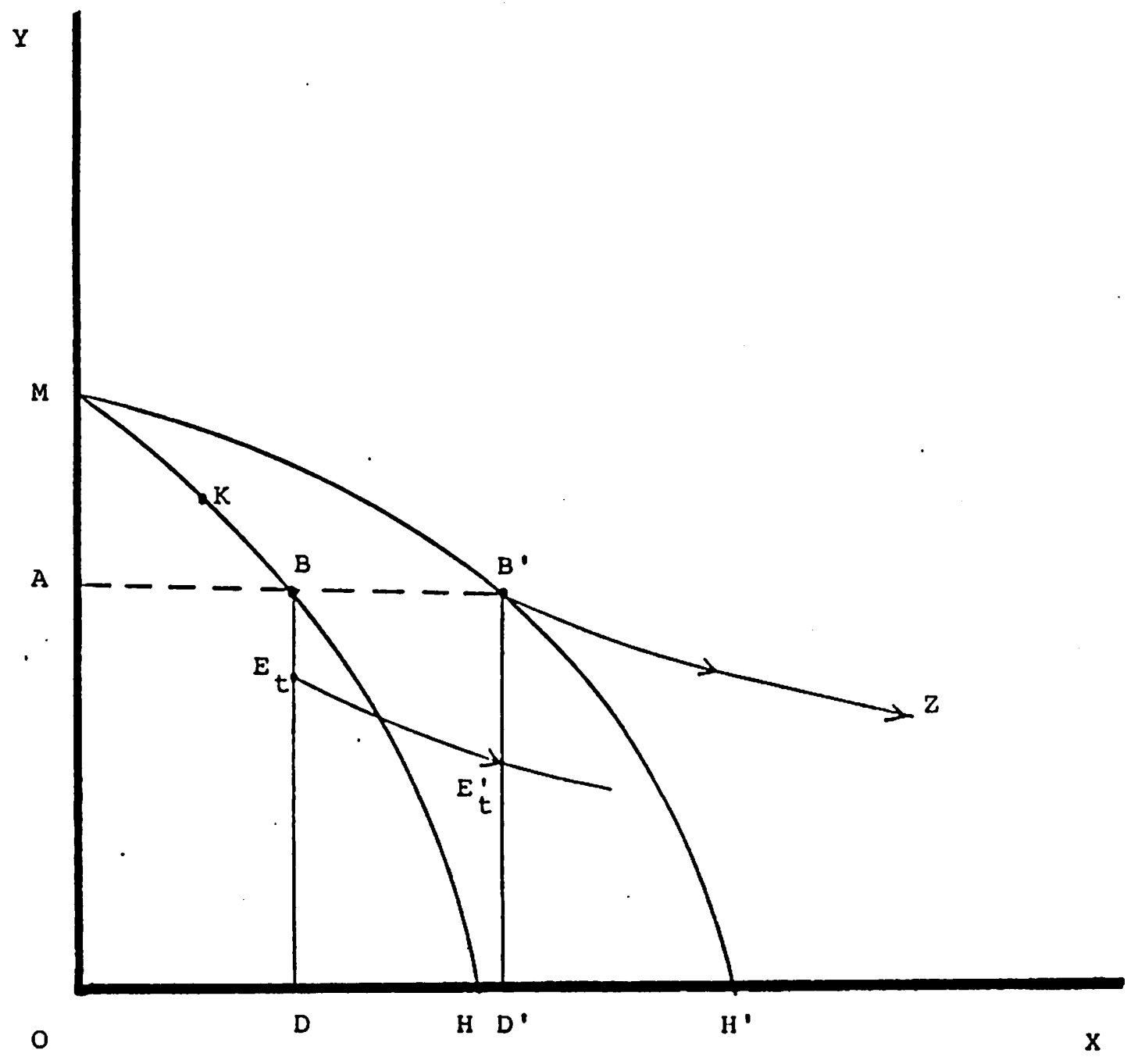

Figure 3 


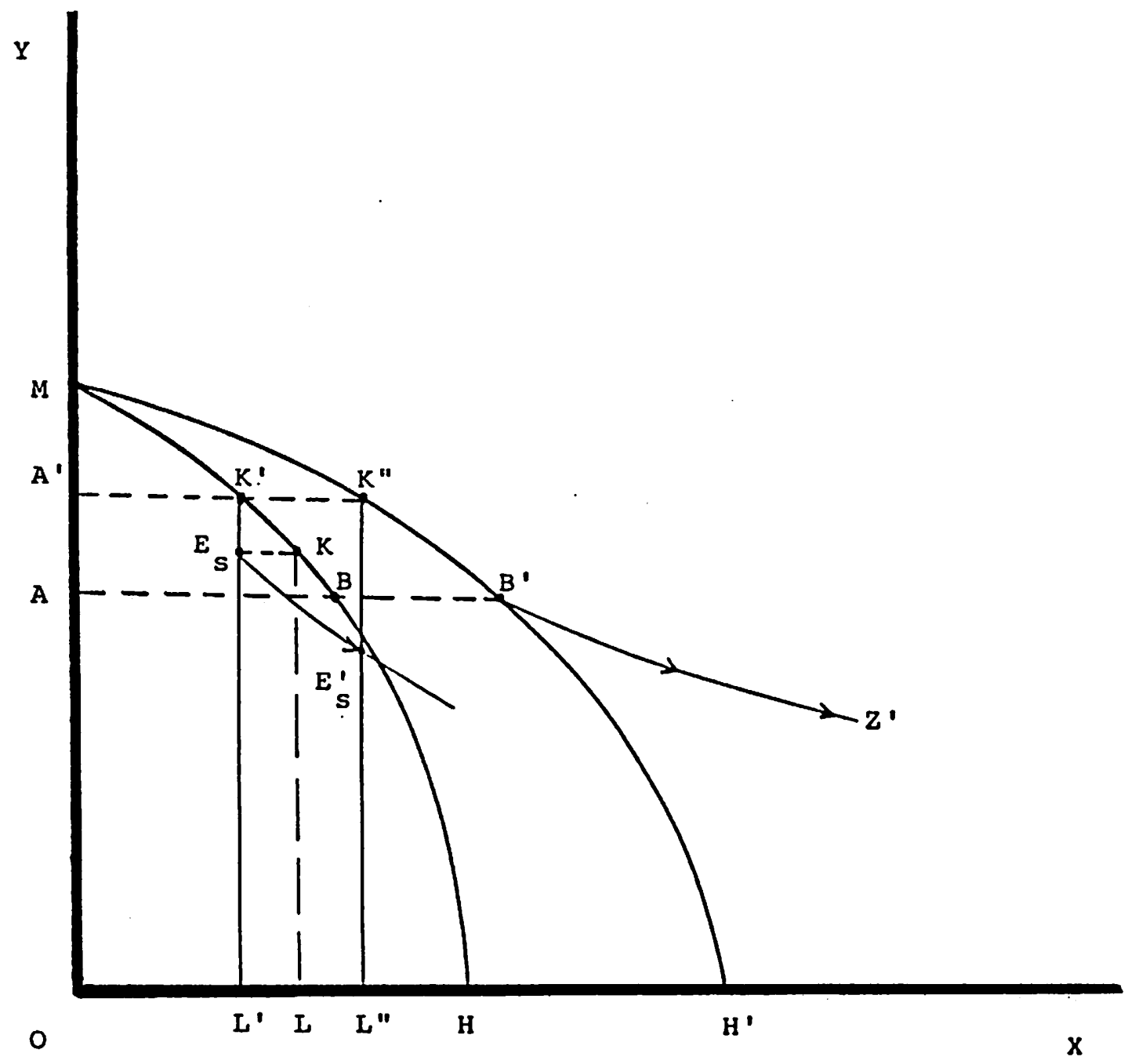

Figure 4 


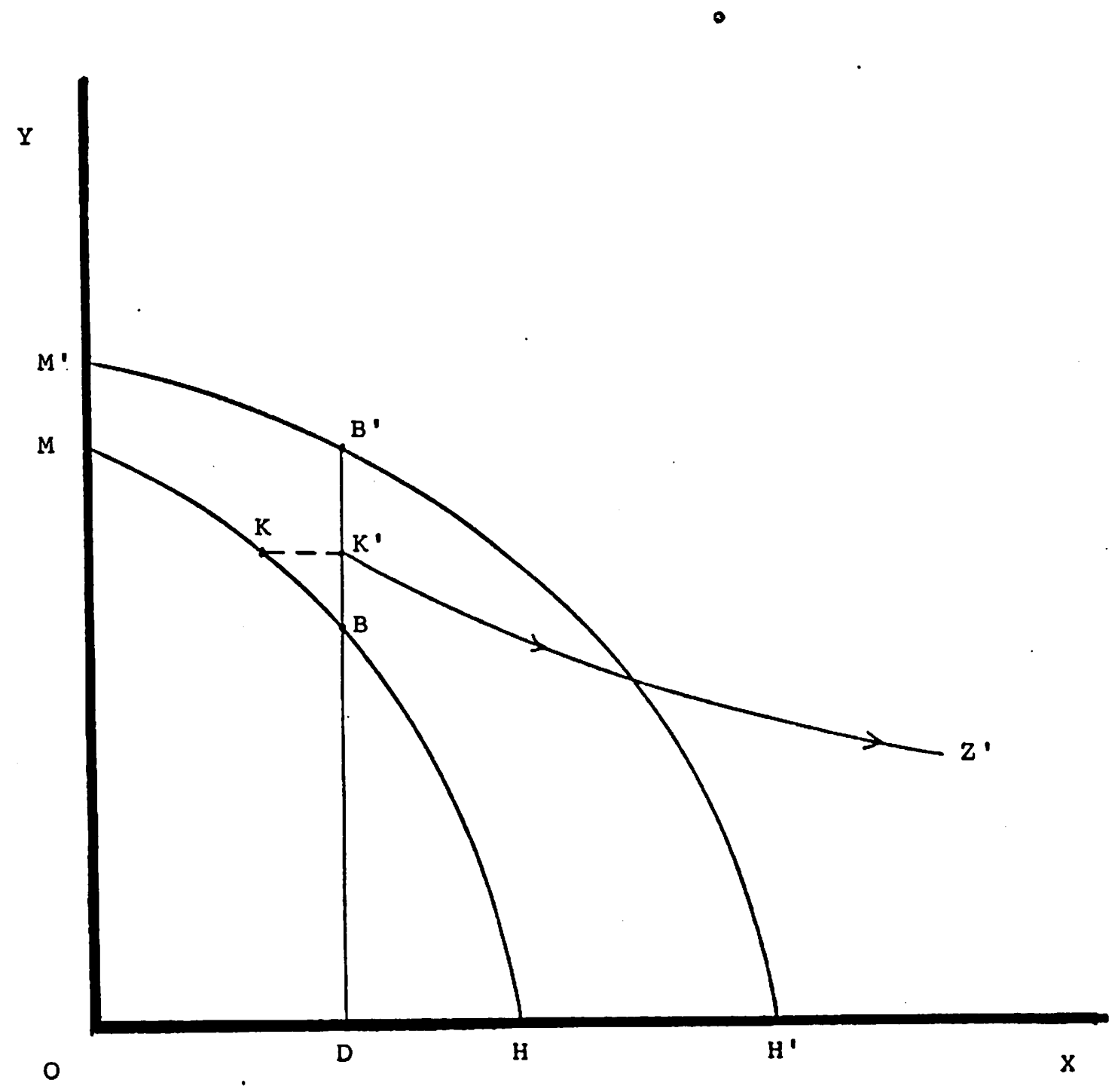

Figure 